\title{
Inadvertent Localized Intensification of Precipitation by Aircraft
}

\section{Moiseev, Dmitry}

2019-02-27

\section{Moiseev , D , Lautaportti , S , Alku , L , Tabakova , K , O'Connor , E , Leskinen , M \&}

Kulmala , M 2019 , ' Inadvertent Localized Intensification of Precipitation by Aircraft ' ,

Journal of Geophysical Research : Atmospheres , vol. 124 , no. 4 , pp. 2094-2104 . https://doi.org/10.1029/2018JD0?

http://hdl.handle.net/10138/304952

https://doi.org/10.1029/2018JD029449

unspecified

publishedVersion

Downloaded from Helda, University of Helsinki institutional repository.

This is an electronic reprint of the original article.

This reprint may differ from the original in pagination and typographic detail.

Please cite the original version. 


\section{JGR Atmospheres}

\section{RESEARCH ARTICLE 10.1029/2018JD029449 \\ Key Points: \\ - Air traffic may affect precipitation in vicinity of airports \\ - Aircraft-produced ice particles increase number concentration of snowflakes \\ - Increased number concentration of snowflakes could lead to localized intensification of precipitation through ice phase "seeder-feeder" process}

Supporting Information:

- Supporting Information S1

- Table S1

- Movie S1

- Movie S2

Correspondence to:

D. Moisseev,

dmitri.moisseev@helsinki.fi

Citation:

Moisseev, D., Lautaportti, S., Alku, L., Tabakova, K., O'Connor, E. J., Leskinen, M., \& Kulmala, M. (2019). Inadvertent localized intensification of precipitation by aircraft. Journal of Geophysical Research: Atmospheres, 124, 2094-2104. https://doi.org/ 10.1029/2018JD029449

Received 7 AUG 2018 Accepted 15 DEC 2018

Accepted article online 12 JAN 2019 Published online 20 FEB 2019

Author Contributions:

Conceptualization: Dmitri Moisseev, Ewan J. O'Connor

Data curation: Dmitri Moisseev,

Laura Alku, Matti Leskinen

Formal analysis: Dmitri Moisseev,

Susanna Lautaportti, Laura Alku,

Ksenia Tabakova, Ewan J. O'Connor,

Matti Leskinen, Markku Kulmala

Funding acquisition: Dmitri

Moisseev

Investigation: Dmitri Moisseev, Susanna Lautaportti, Laura Alku, Ksenia Tabakova, Ewan J. O'Connor, Matti Leskinen, Markku Kulmala Methodology: Dmitri Moisseev, Susanna Lautaportti, Laura Alku, Ksenia Tabakova, Ewan J. O'Connor Supervision: Dmitri Moisseev (continued)

(C)2019. American Geophysical Union. All Rights Reserved.

\section{Inadvertent Localized Intensification of Precipitation by Aircraft}

\author{
Dmitri Moisseev ${ }^{1,2}$ (D), Susanna Lautaportti ${ }^{1}$, Laura Alku³ ${ }^{3}$ Ksenia Tabakova ${ }^{1}$ (D), \\ Ewan J. O'Connor ${ }^{2,4}$ (D), Matti Leskinen", and Markku Kulmala ${ }^{1}$ (iD) \\ ${ }^{1}$ Institute for Atmospheric and Earth System Research/Physics, Faculty of Science, University of Helsinki, Helsinki, \\ Finland, ${ }^{2}$ Finnish Meteorological Institute, Helsinki, Finland, ${ }^{3}$ Vaisala Oyj, Helsinki, Finland, ${ }^{4}$ Department of \\ Meteorology, University of Reading, Reading, UK
}

Abstract Eleven years of dual-polarization weather radar data, complemented by satellite and lidar observations, were used to investigate the origin of areas of localized intensification of precipitation spotted in the vicinity of Helsinki-Vantaa airport. It was observed that existing precipitation is enhanced locally on spatial scales from a few kilometers to several tens of kilometers. The precipitation intensity in these localized areas was 6-14 times higher than the background large-scale precipitation rate. Surface observations and dual-polarization radar data indicate that snowflakes within the ice portion of the falling precipitation in the intensification regions are larger and more isotropic than in the surrounding precipitation. There appears to be an increase in the ice particle number concentration within the intensification region. The observed events were linked to arriving or departing air traffic. We advocate that the mechanism responsible for intensification is aircraft-produced ice particles boosting the aggregation growth of snowflakes.

Plain Language Summary By analyzing 11 years of dual-polarization weather radar observations in the Helsinki region, we have discovered that airplanes landing in or departing from the Helsinki-Vantaa airport could locally increase precipitation rate by as much as 14 times. The observed phenomenon is related to the hole-punch clouds, which are also forming with the help of airplanes. The reported observations allow us to have a better understanding of precipitation formation processes that take place in ice and mixed phase clouds. They show that falling ice crystals from upper clouds could seed lower clouds and therefore increase rain or snowfall intensity through the process called snowflake aggregation. During snowflake aggregation bigger faster falling particles are formed by ice particles colliding and sticking together.

\section{Introduction}

It is known that aircraft can produce ice particles in supercooled liquid clouds (Rangno \& Hobbs, 1983; Woodley et al., 2003). This type of ice particle production may lead to inadvertent cloud seeding or glaciation and formation of hole punch and canal clouds, also known as fallstreak holes. Rangno and Hobbs (1984) and Woodley et al. (1991) have shown that aircraft exhaust is of negligible importance in aircraft-produced ice particle (APIP) formation. The study performed by Woodley et al. (1991) also shows that ice particles can be detected without any evidence for aircraft shedding of ice splinters. The main explanation is that APIP formation is caused by adiabatic cooling; the airflow over aircraft wings adiabatically cools the air locally by about $20{ }^{\circ} \mathrm{C}$, which leads to extremely high supersaturations (Gierens et al., 2009). According to Vonnegut (1986), the expansion of air behind aircraft propeller tips may produce a temperature drop of up to $35^{\circ} \mathrm{C}$. This could lead to condensation and homogeneous freezing of water starting glaciation and rapid growth of ice crystals through the Bergeron-Findeisen process. Pedgley (2008), Heymsfield et al. (2010), and Heymsfield et al. (2011) studied the structure and behavior of hole punch clouds and showed that these can be linked to air traffic. Westbrook and Davies (2010) documented the microphysics and dynamics of hole punch clouds by using ground-based remote sensors: ceilometer and radar. Furthermore, Heymsfield et al. (2011) have argued that APIPs could lead to an increase of precipitation intensity in the vicinity of airports.

In the Helsinki region it is not uncommon to observe localized intensification of precipitation (LIP) occurring within a larger area of widespread precipitation. In this article we report 17 days during which multiple LIPs were observed. The observed spatial and temporal scales of LIP were on the order of a few kilometers and 30 to $60 \mathrm{~min}$. The precipitation intensification is often seen in weather radar images, 
Writing - original draft: Dmitri Moisseev, Susanna Lautaportti Writing - review \& editing: Dmitri Moisseev, Susanna Lautaportti, Laura Alku, Ksenia Tabakova, Ewan J. O'Connor, Matti Leskinen, Markku Kulmala where radar effective reflectivity factor $\left(Z_{e}\right)$ values show local narrowband-like features, that is, trails; and, in the range height indicator (RHI) scans, these features appear as "streamers." A comparison of the precipitation intensity within and outside of LIP events shows increases in the observed precipitation rate of factors of 2 to 10 . Polarimetric radar variables, such as $Z_{\mathrm{dr}}$ and $\rho_{\mathrm{hv}}$, inside and outside of the ice portion of LIP are detectably different, indicating changes in snowflake physical properties and therefore in the growth processes that lead to their formation. The observed signatures are similar to the ones recorded in the snowgenerating cells (Kumjian et al., 2014). The observed features are matched with individual aircraft, either arriving or departing from Helsinki-Vantaa airport.

The observed phenomena appear to be related to hole punch clouds as suggested by Heymsfield et al. (2011). In the observed LIP events, however, we observe the modification of preexisting precipitation and not the glaciation of a single supercooled liquid cloud layer. There are often several cloud layers present, with APIPs seeding lower cloud layers. Even though we argue that LIP has an anthropogenic cause, the reported phenomenon demonstrates how cloud-to-precipitation processes work in mixed-phase clouds and what processes may be responsible for the intensification of precipitation occurring under natural conditions. It demonstrates that aggregation growth of snowflakes and ice phase cloud seeding are important processes in multilayer clouds, as discussed in, for example, Moisseev et al. (2015) and Schrom and Kumjian (2016), augmenting the analysis presented by Verlinde et al. (2013), Moisseev et al. (2017), Kumjian et al. (2016, 2014), and Giangrande et al. (2016) discussing the importance of riming.

\section{Measurements}

For this study we used Kumpula weather radar effective reflectivity factor $\left(Z_{e}\right)$ and differential reflectivity $\left(Z_{\mathrm{dr}}\right)$ observations from December 2008 to January 2018. The Kumpula (KUM) C-band weather radar is a dualpolarization radar system installed at the University of Helsinki Kumpula campus. It is located on the top of the Department of Physics building at approximately $30 \mathrm{~m}$ above ground level. To aid characterization of the observed phenomena, both plan position indicator (PPI) and RHI scans were analyzed. Both sets of scans were performed within the same 10- to 15-min time interval. The radar observations presented here were processed using the Python ARM Radar Toolkit (Py-ART; Helmus \& Collis, 2016).

During one event, several LIP passed over the University of Helsinki surface precipitation measurement site in Järvenpää (60.48 N, 25.07 E), where we utilized a Particle Video Imager, PVI (Newman et al., 2009) to obtain information on the particle size distribution at the surface both within and outside LIP. The PVI is a particle imager that uses a digital camera to record particles that fall between the camera and backlight lamp. The lamp is located approximately $2 \mathrm{~m}$ from the camera. Because of the open fetch the measurement setup minimizes the impact of wind on falling precipitation particles. PVI records shadow images of the particles falling through the focal point from which the particle size distribution is calculated and a general understanding of the particle type can be inferred.

To investigate what role supercooled liquid cloud layers play in forming LIP, a Doppler lidar and satellite data were used in addition to the radar observations to study several cases from 2009-2013. The Halo Doppler lidar, located in Kumpula, operates at a wavelength of $1.5 \mu \mathrm{m}$ and provides vertical profiles of attenuated backscatter coefficient, Doppler velocity, and the depolarization ratio with high spatial and temporal resolution (Hirsikko et al., 2014). These parameters were used to detect the presence and location of the lowest supercooled liquid layer using the method described in Hogan et al. (2003) and corroborated with low values of the depolarization ratio, as discussed in section 3.

For some of the events, MODIS (Moderate Resolution Imaging Spectroradiometer) data from the satellites Terra and Aqua were used to estimate the upper cloud phase and cloud top height (MOD06 and MYD06 level 2 data). Radiosoundings from Jokioinen (approximately $100 \mathrm{~km}$ NW from Kumpula) and satellite cloud top temperature data were used to provide the prevailing conditions at the LIP formation height and cloud top.

\section{Data Analysis and Results}

\subsection{LIP Identification}

The first step of the study is the case selection. Since the installation of the Kumpula radar in late 2004, the list of interesting radar events is maintained by one of the coauthors (M. L.). It was observed that in some 

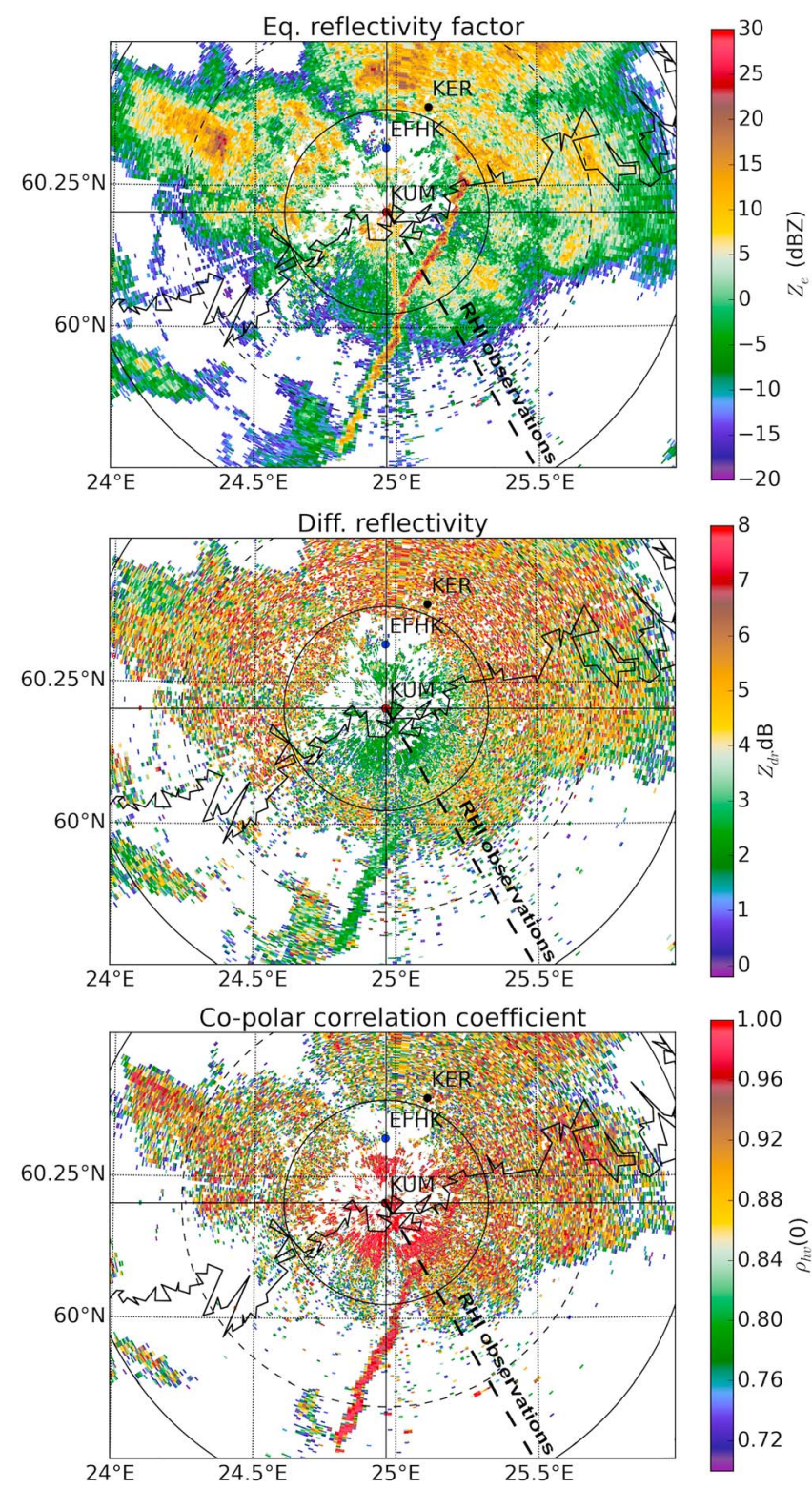

Figure 1. PPI scan of $Z_{h}, Z_{\mathrm{dr}}$, and $\rho_{\mathrm{hv}}$ observations recorded by Kumpula radar at an elevation angle of $0.5^{\circ}$ on 11 December 2008 at 0730 UTC. Range rings are shown every $20 \mathrm{~km}$. A trail of enhanced reflectivity factor is clearly visible and consistent with an aircraft approach path to HelsinkiVantaa airport (EFHK). Kumpula radar range height indicator observations, shown in Figure 2, transect the trail and the dashed line shows the projection of the range height indicator measurement plane on the plan position indicator scan. cases, low elevation angle PPI observations exhibit linear or piecewise linear enhanced reflectivity features, as presented in Figures 1 and 2. The dual-polarization observations in these areas are also different from those in the surrounding large-scale precipitation. Days during which low elevation angle PPI observations exhibited features similar to ones shown in Figures 1 and 2 were selected for further study. Typically, during these days more LIP signatures were observed and further analyzed. A list of all such events is given in Table $\mathrm{S} 1$ in the supporting information.

As the result of the case selection, 17 event days were identified. During these days, multiple LIP cases were observed. The total number of identified LIP exceeds 60, of which 23 had supporting satellite and/or lidar data. Since the focus of this study is to understand the physical processes responsible for LIP, we focus on the 23 cases where supplementary observations either by lidar and/or satellite are available. The LIP events analyzed in more detail are listed in Table 1 together with the supporting data availability.

\subsection{Matching LIP to Aircraft Paths}

To verify our inference that the observed phenomenon is caused by aircraft, we have examined the individual flightpaths at the time of LIP events. The aircraft data are available from a web service Planefinder (http://planefinder.net/; last accessed on 29 May 2018). This web service data go back to April 2011, so connecting LIP cases to air traffic is only possible beginning on this date. It was observed that in most cases, before the Kumpula (or Kerava) radar detects a LIP event, there was at least one aircraft present in the area of interest (within 2-10 km from the observed feature). The distance between the flight path and LIP is determined by the advection of precipitation. In most cases an aircraft would be approaching the Helsinki-Vantaa airport at an altitude of 3,000 to $3,400 \mathrm{~m}$ and then rapidly descend in the vicinity of the airport. Therefore, if the cloud layer height coincides with the approach altitude, the resulting LIP has an elongated shape and can extend over several kilometers. In cases where the cloud layer is penetrated during rapid descent or ascent the LIP is more localized. The LIP shape and its relation to the aircraft flightpath is similar to hole punch and canal clouds (Heymsfield et al., 2010).

Given that the LIP cases were identified in low-level PPI scans, there was about 30- to 40-min time lag between the corresponding aircraft track and observed precipitation enhancement. This time lag was considered while matching the aircraft track and LIP radar signatures. The time delay effect is clearly visible in Figure 3, which shows RHI observations that transect the LIP shown in Figure 1. The figure shows that the RHI scan at 0655 UTC exhibits reflectivity enhancement at $15-\mathrm{km}$ range and altitudes between 2,000 and 2,500 $\mathrm{m}$. This feature reaches the ground at 0725 UTC.

The observed LIP signatures and aircraft flight paths were matched based not only on the distance between the two but also on their appearance. For a good match flight path geometry should match the appearance of LIP. Examples of such matches are shown in the supporting information.

\subsection{LIP Height Analysis}

We hypothesize that LIP are caused by APIPs that glaciate/grow in a supercooled liquid cloud layer and these particles seed lower precipitating cloud. This implies that there should be a liquid cloud layer above the precipitation. This cloud layer is not likely to be visible in radar observations, though, as the cloud 

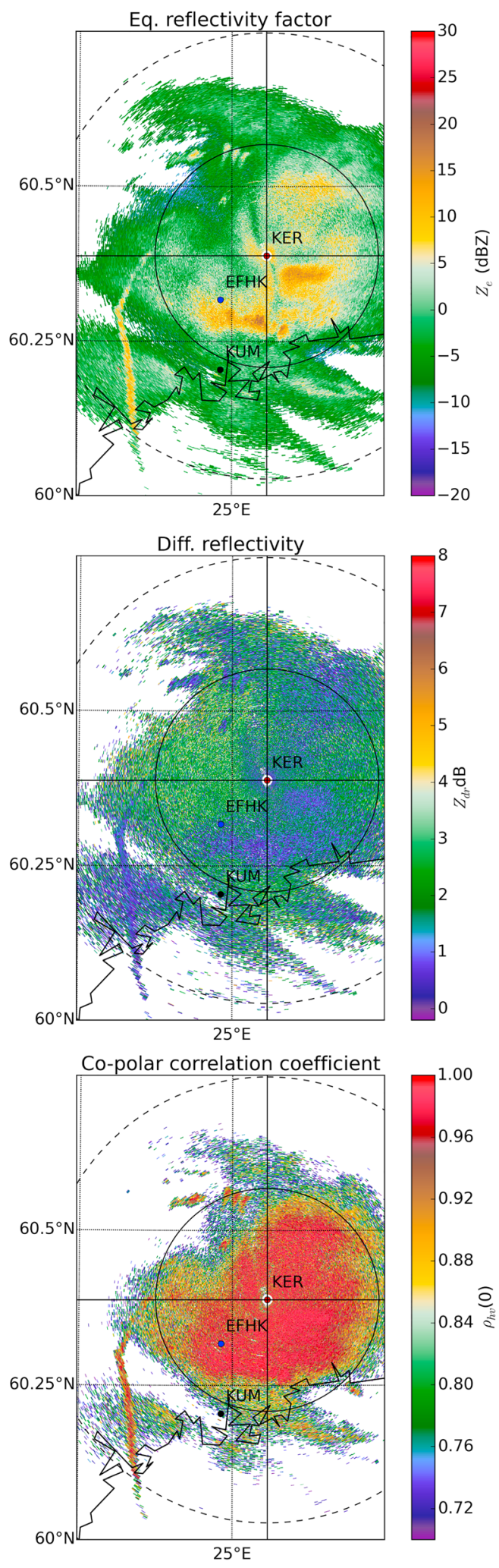

Figure 2. Plan position indicator scan of $Z_{h}, Z_{\mathrm{dr}}$, and $\rho_{\mathrm{hv}}$ observations recorded by Kerava radar at an elevation angle of $1.5^{\circ}$ on 10 March 2009 at 0924 UTC. Range rings are shown every $20 \mathrm{~km}$. Similar to Figure 1, a trail of enhanced reflectivity factor is clearly visible and consistent with an aircraft approach path to Helsinki-Vantaa airport (EFHK). droplets are too small. The air temperature in this layer should be around -15 to $-20^{\circ} \mathrm{C}$, such that adiabatic air expansion behind aircraft wings or propellers would lead to condensation and homogeneous ice nucleation (Heymsfield et al., 2010).

Given that radar observations may not be sensitive enough to detect liquid cloud layers where LIP are originating, data from MODIS and lidar are also analyzed for several events. Figure 4 shows the height information for individual LIP cases. The precipitation top height (Figure 4: blue squares) is determined from the RHI scans where precipitation is diagnosed $(Z \geq-10 \mathrm{dBZ})$ at $10-\mathrm{km}$ distance from the radar.

The initiation height of LIP was determined for 21 cases (Figure 4: black dots) by visually inspecting the RHIs and PPIs and identifying where the streamer (high $Z$ and small $Z_{\mathrm{dr}}$ compared to the surrounding area, see Figures 1 and 2) is first detected. It should be noted that these cases were selected based on the procedure discussed in the previous section.

A total of 19 LIP cases had simultaneous Doppler lidar data available, and an example from 26 January 2012 is shown in Figure 5. Very strong scattering is exhibited by liquid water layers at lidar wavelengths due to the high droplet number concentration, usually $>10^{8} \mathrm{~m}^{-3}$. The spherical liquid water droplets are small, typically $<20 \mu \mathrm{m}$ in diameter, so have negligible terminal fall velocities (a few centimeters per second), and are not depolarizing. The presence of liquid water in a vertical profile is diagnosed when three conditions are met: high values of attenuated backscatter (Figure 5: top) coincide with low depolarization values (Figure 5: bottom) and Doppler velocities (Figure 5: center) are close to 0. However, the lidar signal is rapidly attenuated in liquid clouds, so that it is only possible for a ground-based lidar to detect the base of the first liquid layer it encounters, with little information about its vertical extent. A significant amount of liquid water was detected in the lidar data for all 19 LIP cases, and the altitude of the base of the liquid layer in these 19 cases is shown in Figure 4 (red circles).

Satellite data were used to determine the vertical extent of the liquid layer and to ascertain whether there were another liquid layer present above. Coincident satellite data were available in nine cases (see Table 1) in a $100-\mathrm{km} \times 100-\mathrm{km}$ area around the Kumpula radar. In eight cases, at least $20 \%$ of the observation area was covered with mixed or water phase clouds. For these eight cases the mean mixed or water phase cloud top heights were calculated from the MODIS cloud top pressure data (Figure 4, magenta triangles). In the remaining case (15 February 2013) MODIS detected only ice phase clouds but note that the MODIS cloud phase product only determines the phase of the highest cloud layer with no information for any intervening clouds beneath.

This analysis shows that LIP originates at or above the precipitation top. Given the radar sensitivity, only LIPs at a relatively mature stage can be detected, which may explain why in most cases LIP and radar-based cloud top heights coincide. The satellite data analysis shows that, in the majority of cases analyzed, there is an indication that a supercooled cloud layer is present above the precipitation.

\subsection{Temperature}

To identify the temperatures at which LIP are formed, radio sounding and satellite measurements of air temperature were analyzed for the selected 
Table 1

Date and Time of the Streamers and Available Instruments

\begin{tabular}{|c|c|c|c|c|c|}
\hline \multirow[b]{2}{*}{ Date } & Radar & Satellite & Lidar & PVI & Sounding \\
\hline & $\begin{array}{l}\text { Time } \\
\text { (UTC) }\end{array}$ & $\begin{array}{l}\text { Time } \\
\text { (UTC) }\end{array}$ & & & \\
\hline \multirow[t]{3}{*}{10 March 2009} & 9:13:09 & 09:15 (T) & & & $\mathrm{X}$ \\
\hline & 9:16:16 & 09:15 (T) & & & $\mathrm{X}$ \\
\hline & 18:39:12 & $18: 55(\mathrm{~T})$ & & & $\mathrm{X}$ \\
\hline \multirow[t]{6}{*}{26 January 2012} & $4: 53: 37$ & & $\mathrm{X}$ & & $\mathrm{X}$ \\
\hline & $5: 22: 37$ & & $\mathrm{X}$ & & $\mathrm{X}$ \\
\hline & $5: 23: 40$ & & $\mathrm{X}$ & & $\mathrm{X}$ \\
\hline & $5: 33: 38$ & & $\mathrm{X}$ & & $\mathrm{X}$ \\
\hline & 6:02:36 & & $\mathrm{X}$ & & $\mathrm{X}$ \\
\hline & $6: 52: 34$ & & $\mathrm{X}$ & $\mathrm{X}$ & $\mathrm{X}$ \\
\hline \multirow[t]{7}{*}{11 February 2012} & 10:03:39 & 09:40 (T) & $\mathrm{X}$ & & $\mathrm{X}$ \\
\hline & $11: 13: 41$ & $11: 15(\mathrm{~T})$ & $\mathrm{X}$ & & $\mathrm{X}$ \\
\hline & $12: 33: 38$ & & $\mathrm{X}$ & & $\mathrm{X}$ \\
\hline & $15: 43: 39$ & & $\mathrm{X}$ & & $\mathrm{X}$ \\
\hline & $17: 42: 37$ & & $\mathrm{X}$ & & $\mathrm{X}$ \\
\hline & $18: 23: 39$ & & $\mathrm{X}$ & & $\mathrm{X}$ \\
\hline & 19:02:30 & 19:15(T) & $\mathrm{X}$ & & $\mathrm{X}$ \\
\hline 15 January 2013 & $23: 50: 12$ & $23: 50$ (A) & & & X (Tallinn) \\
\hline \multirow[t]{5}{*}{16 January 2013} & $5: 42: 48$ & & $\mathrm{X}$ & & X (Tallinn) \\
\hline & 6:17:19 & & $\mathrm{X}$ & & $\mathrm{X}$ \\
\hline & 6:42:48 & & $\mathrm{X}$ & & $\mathrm{X}$ \\
\hline & 8:42:49 & & $\mathrm{X}$ & & $\mathrm{X}$ \\
\hline & $9: 12: 47$ & 09:15 (T) & $\mathrm{X}$ & & $\mathrm{X}$ \\
\hline 15 February 2013 & $18: 50: 41$ & 19:05 (T) & $\mathrm{X}$ & & $\mathrm{X}$ \\
\hline
\end{tabular}

Note. In the satellite column $\mathrm{T}$ indicates Terra and $\mathrm{A}$ indicates Aqua. PVI stands for Particle Video Imager. cases. In Figure 6, temperatures at the heights where LIPs, appearing as a streamer in RHI observations, were first detected are shown and compared to the MODIS cloud top temperature product, calculated as the mean cloud top temperature in the region where mixed or water phase clouds were detected. The temperature for LIP detection height from -10 to $-15^{\circ} \mathrm{C}$ and these values are somewhat warmer than expected for the formation of APIPs (Heymsfield et al., 2010; Heymsfield et al., 2011; Pedgley, 2008).

During the analysis, we noticed that, in the majority of cases, aircraft approach the Helsinki-Vantaa airport at altitudes between 2,500 and $3,000 \mathrm{~m}$ before their final descent; hence, the temperature at $3000 \mathrm{~m}$ is shown in Figure 6. Additionally, the 5,000-m temperature gives an indication of the lowest temperature likely to be of importance in the observed cloud processes. Both Kumpula and Kerava radars are research radars with scan strategies that are modified according to research needs. Because of this the temporal resolution of measurements used to detect formation of LIP is 5 to $15 \mathrm{~min}$. This temporal resolution means that LIPs could have formed up to 300 to $900 \mathrm{~m}$ above the height where they were detected, assuming a snowflake fall velocity of $1 \mathrm{~m} / \mathrm{s}$. This would put the LIP formation height closer to the cloud top, in temperatures closer to the expected range in which LIP would form.

\subsection{Snowfall Rate}

From the recorded PPI measurements we have identified 11 days where the aircraft-induced snowfall reached the ground level; see Table S1 in the supporting information. For these days we have computed the snowfall rate, $Z_{\mathrm{dr}}$, and copolar correlation coefficient values using observations inside the trails and immediately outside the trails using the lowest available PPI observations.

The snowfall rate, $S$, is derived from radar reflectivity, $Z$. To consider potential uncertainties, the snowfall rate values were calculated using two distinct $Z-S$ relationships; the Finnish Meteorological Institute climatological relationship (Saltikoff et al., 2010),

$$
Z=100 \cdot S^{2}
$$

where $S$ is in millimeters per hour and $Z$ is the equivalent radar reflectivity factor in millimeters to the sixth power per meter cube; and

$$
Z=210.72 \cdot S^{1.63}
$$

by Huang et al. (2015).

The comparison of $S$ and $Z_{\mathrm{dr}}$ values inside and outside the streamers is shown in Figure 7 for all the recorded cases. In every case the snowfall rate (Figure 7) is larger inside than outside the streamer; the snowfall rate can be as much as 6 times higher within LIP. On average, the equivalent reflectivity values were observed to be $14 \mathrm{~dB}$ larger inside of LIP. The average $Z_{\mathrm{dr}}$ values (Figure 7) are about 4 times smaller inside the LIP indicating that particles inside the streamers are more spherical and/or less dense than those outside. This is also supported by larger copolar correlation coefficient values inside of LIP. It should be noted, that in some cases, $Z_{\mathrm{dr}}$ values inside of LIP were higher than expected from aggregates (Li et al., 2018; see, e.g., Figure 3), that is, around $2 \mathrm{~dB}$, which may be attributed to a mixture of crystals and snowflake aggregates (Keat \& Westbrook, 2017).

Of course, the $Z_{e}-S$ relations inside and outside of LIP may be different. von Lerber et al. (2017) have shown how the prefactor in $Z_{e}-S$ relations depends on the intercept parameter of the particle size distribution. Assuming that aircraft-induced ice particles would increase the number concentration of ice particles and 

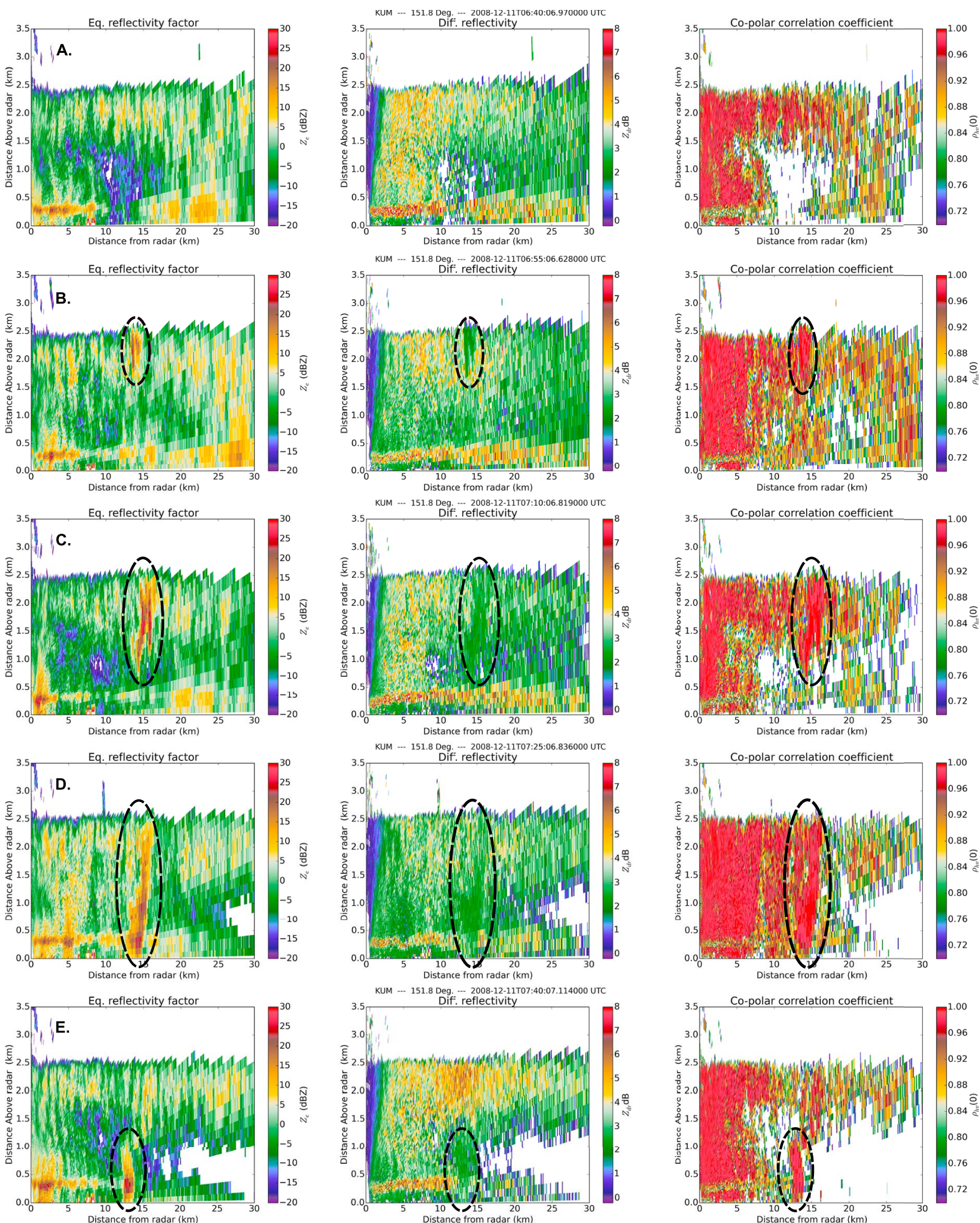

Figure 3. (a-e) A sequence of RHI observations (azimuth angle $151.8^{\circ}$ ) recorded every 15 min starting at 0640 UTC, just before the formation of the streamer responsible for the enhanced reflectivity trail shown in Figure 1. Panel (d) shows measurements recorded at 0725 UTC that are closest in time to the plan position indicator measurements shown in Figure 1. 


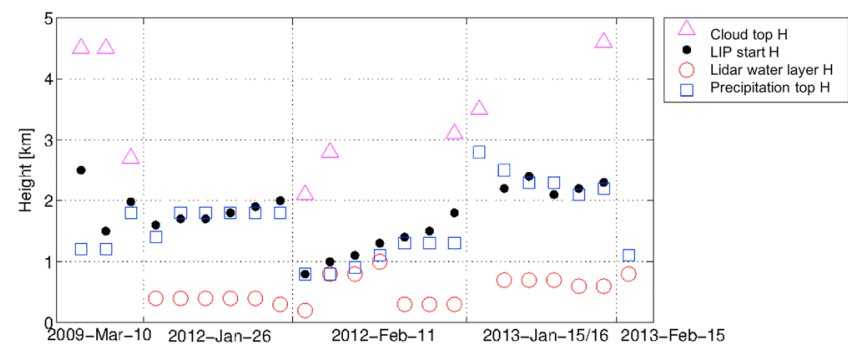

Figure 4. Precipitation top height (blue squares), liquid cloud base detected by lidar (red circles), localized intensification of precipitation (LIP) initiation height (black dots), and water or mixed phase cloud top height (magenta triangles) for each LIP. therefore the particle size distribution intercept parameter, $Z_{e}-S(2)$ would be more applicable to the regions outside of LIP and (1) to the regions inside. This is of course just an estimate of the potential difference in the $Z_{e}$-S relation. If this is the case, then the difference between precipitation rate is even larger and the snowfall rate inside of LIP is about 14 times higher than outside.

\subsection{Particle Size Distribution}

Several LIP events were detected in PPIs on 26 January 2012. Several of these trails passed over our measurement site in Järvenpää, $32 \mathrm{~km} \mathrm{NE}$ of the Kumpula radar, as can be seen in Figure 8. During the event, the Kumpula radar was performing regular RHI scans over the Järvenpää measurement site. Figure 9 shows the three consecutive RHIs from this time period. These observations were selected to show the evolution of the most pronounced LIP, arriving over the measurement site at 0700 UTC.

Based on these RHIs, we estimate that the LIP moves at approximately $9 \mathrm{~m} / \mathrm{s}$. The LIP front edge $(Z>10 \mathrm{dBZ}$ and $Z_{\mathrm{dr}}<0.5 \mathrm{~dB}$ ) reaches the measurement site at 6:55:30 UTC, the overpass of the feature takes $7 \mathrm{~min}$, and the event is over at 7:03:30 UTC.

The impact of LIP on the particle size distribution is investigated with the 1-min average particle size distribution data recorded by PVI. The total number concentration $N_{t}$ and the slope parameter $\Lambda$ of an assumed
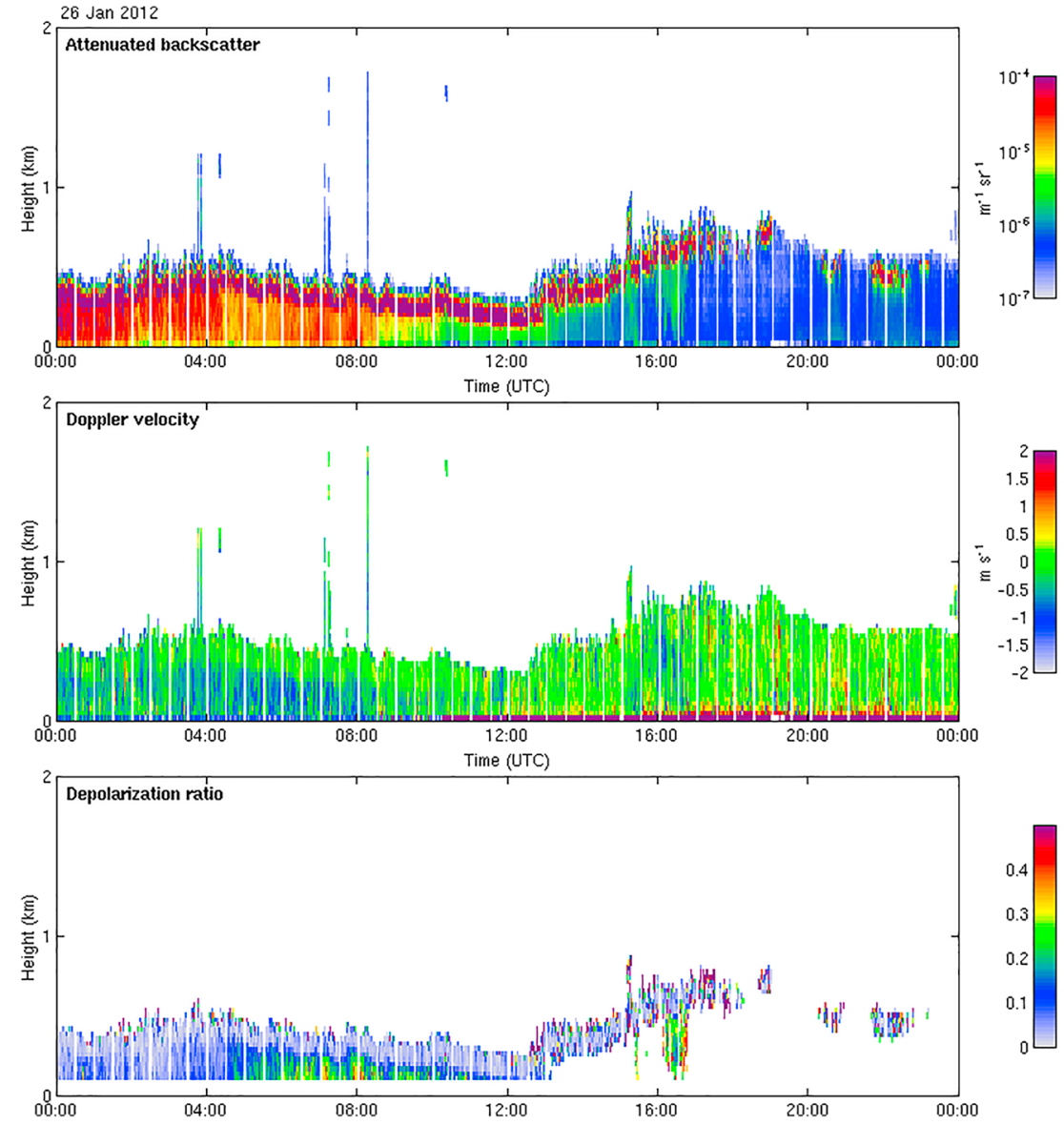

Figure 5. Doppler lidar data at Kumpula on 26 January 2012. (top) Attenuated backscatter coefficient, (center) Doppler velocity, and (bottom) depolarization ratio. 


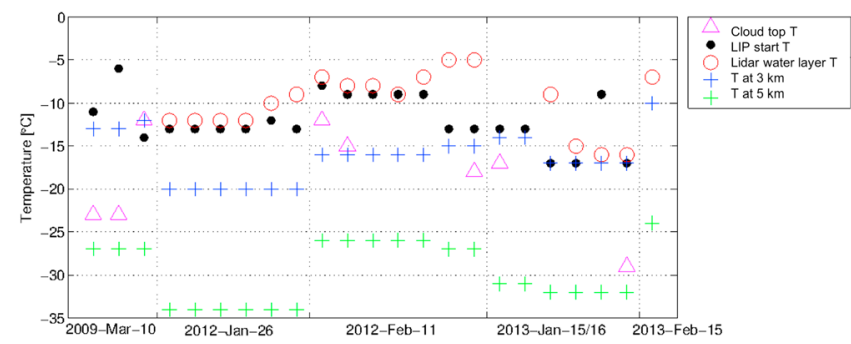

Figure 6. Temperatures at different altitudes: lowest water layer height (red circles), streamer start height (black dots), cloud top (magenta triangles), 3-km height (blue plus signs), and 5-km height (green plus signs) LIP $=$ localized intensification of precipitation. exponential particle size distribution were calculated from PVI data. Taking into account the difference in sampling times between the radar and PVI, we consider that the PVI data recorded between 6:58 and 7:02 UTC corresponds to the passage of LIP, and data recorded before 6:54 UTC and after 7:06 UTC as outside the LIP. PVI data recorded at time intervals 6:55-6:57 and 7:03-7:05 are considered to be of an undetermined nature, meaning that the radar data sampling does not allow us to make a definitive classification. The evolution of $N_{t}$ and $\Lambda$ is shown in Figure 10, and one can see that the overall trend is that, within an LIP event, there are more particles and that they are larger; that is, $\Lambda$ is smaller. It should be noted that around 0645 UTC there was another LIP over the measurement site, see Figure 8, but since its boundaries were less well defined, it was not included in the study even though it shows similar $N_{t}$ behavior (Figure 10).

\section{Summary and Discussion}

By analyzing weather radar data collected during eleven years in the Helsinki region, 17 days during which several localized precipitation intensification events were identified. From these cases, supplementary lidar and/or satellite data were available for 23 events, corresponding to 6 days, and were analyzed in this study. Unfortunately, due to the local nature of the phenomena, and a fixed radar scanning strategy, the precise determination of the LIP initiation height is not always possible. Nonetheless, it appears to be higher than the precipitation top height as detected by the radar. Actually, in about $70 \%$ of the investigated cases LIP is detected to begin above the highest existing precipitation layer (Figure 3). In the remaining cases they may have formed above, but due to the measurement configuration, we were not able to detect them early enough.

In all cases with lidar data available, the lidar detected liquid water layers. The lowest layer was always below the precipitation top height. As can be seen from Figure 5, on 26 January 2012 the lidar detected liquid cloud base height is at about $500 \mathrm{~m}$ above the ground. In Figure 9, we can see that the precipitation intensity is intensified in the layer where the water is present. However, the LIP in this case originates at an altitude of $2 \mathrm{~km}$ or higher, and the lowest liquid cloud layer is not essential for the formation of LIP.
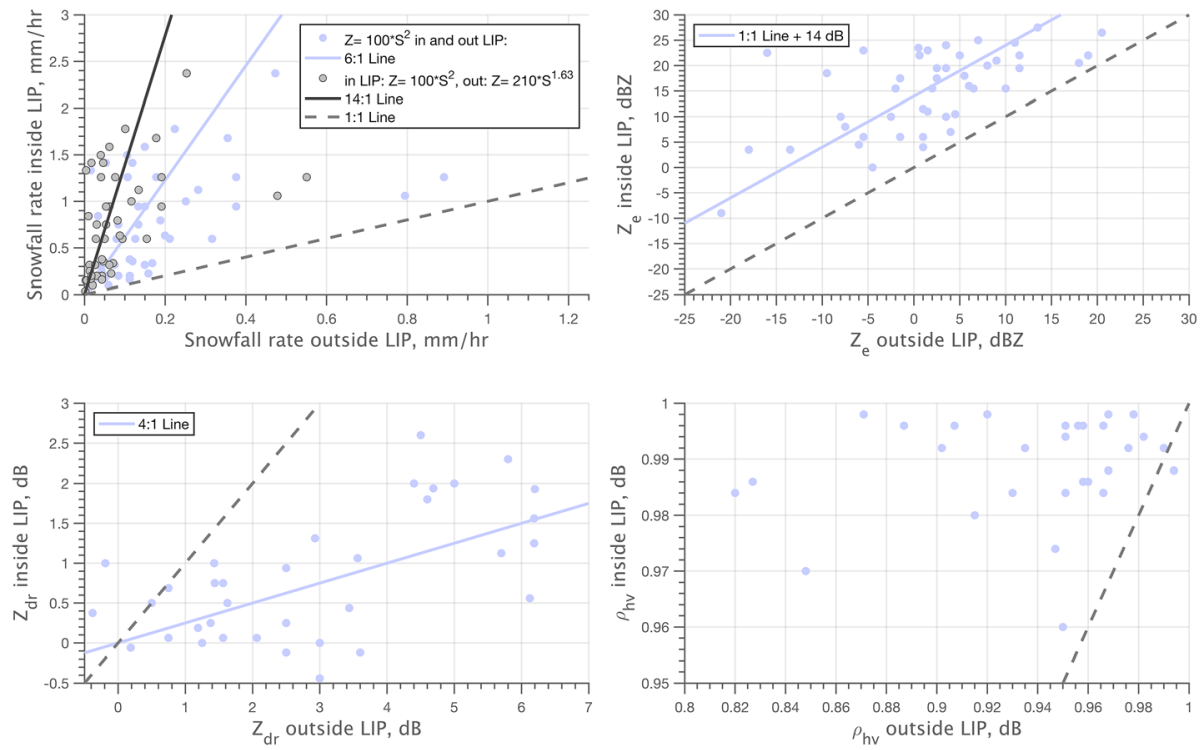

Figure 7. Snowfall rate and reflectivity, differential reflectivity, and copolar correlation coefficient inside and outside the localized intensification of precipitation (LIP) regions. 

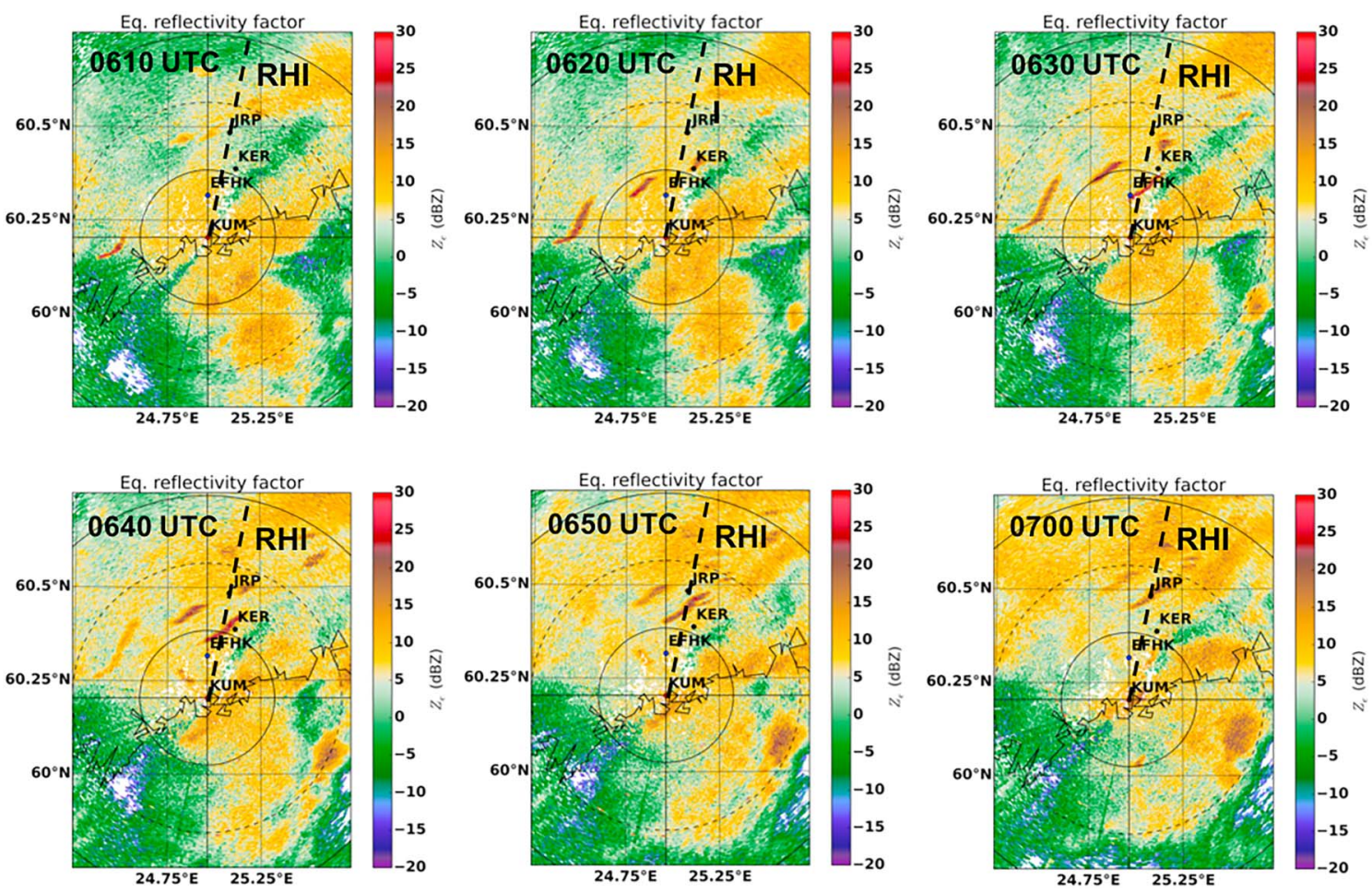

Figure 8. Kumpula radar plan position indicator scans of equivalent reflectivity factor on 26 January 2012. Several localized intensification of precipitations are observed in the EFHK approach area. Two localized intensification of precipitations pass over the Jarvenpää measurement site at 0640 and 0700 UTC.

Since lidar is only capable of detecting the lowest liquid layer, satellite data were used to investigate whether there is an upper liquid cloud layer. In all cases, except for 15 February 2013, satellite data indicated the presence of a supercooled liquid or mixed-phase cloud layer above the precipitation. By comparing the LIP (Figure 4: black dots) and cloud top heights (Figure 4: magenta triangles) we can see that the LIP initiation height is well below the upper cloud top height in all the cases where satellite data was available. The fact that LIP is initiated above precipitation (as defined in this study) but below cloud top indicates that the initiation height of the streamer might be underestimated, partially because the start of the streamer formation cannot be seen with C-band radar since the particle size is too small. The analysis of the flightpaths confirms that aircraft were present at the altitudes where LIP are formed. It is, however, not clear whether the
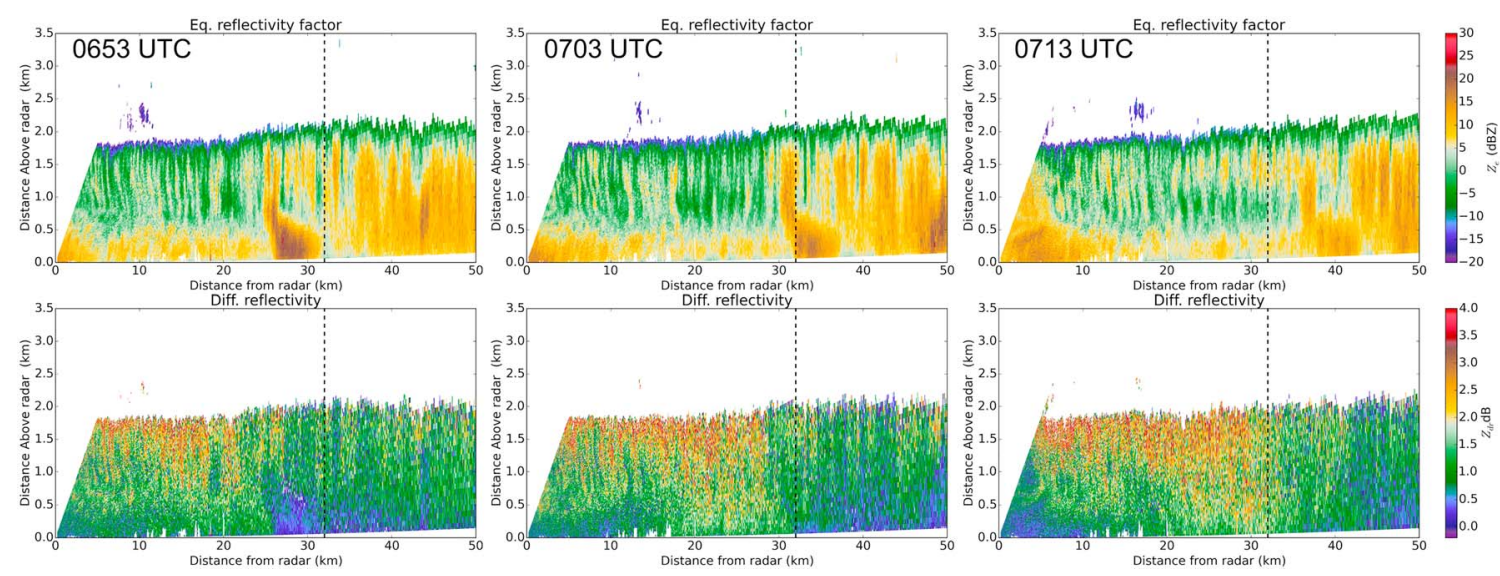

Figure 9. Evolution of the streamer on 26 January 2012. (upper panels) $Z$ and (lower panels) $Z_{\mathrm{dr}}$. The location of the Järvenpää measurement site is indicated with the black dashed line. 

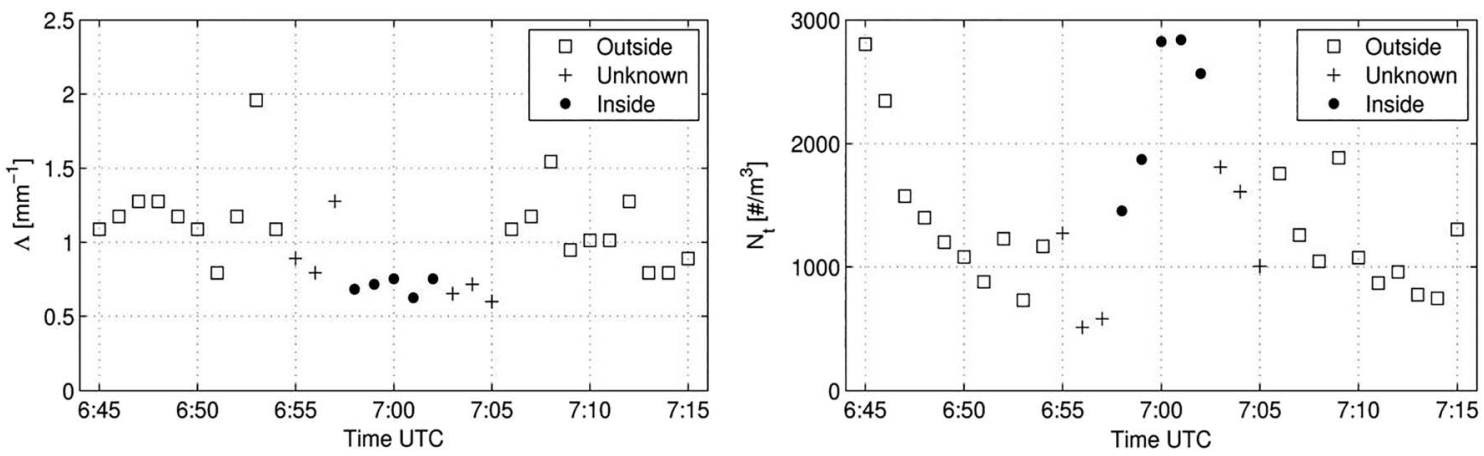

Figure 10. $N t$ (right) and $\Lambda$ (left) inside (dots) and outside (squares) the streamers. The plus signs indicate data that cannot be clearly identified as belonging to inside or outside of localized intensification of precipitation.

precipitation originates from the same cloud as detected by satellites. There are two potential scenarios: one where there are at least two cloud layers and the upper layer is perturbed by aircraft with APIPs seeding the lower precipitating cloud and one where there is only one cloud precipitating cloud layer, penetrated by an aircraft and APIPs are generated. In both scenarios, APIPs increase the number concentration of snowflakes, and therefore, the probability of ice-ice collision also increases, which leads to more efficient aggregation growth of snowflakes (Hobbs et al., 1974). A schematic drawing of the second scenario is shown in Figure 11. In the supporting information additional LIP examples are presented. On 24 February 2011 a number of LIP were detected as shown in Figure S1. The RHI measurements presented in the animation MS1 show that LIPs are formed in the cloud layer that is not detected by the radar. However, around 0530 UTC this layer becomes visible, possibly due to larger scale glaciation. This supports our inference that LIP originate in supercooled liquid layers located above existing precipitation.

The temperatures at the LIP starting height are usually not cold enough (requirement is $T \leq-15^{\circ} \mathrm{C}$ ) to produce homogenous freezing by cooling due to expansion of air over the aircraft wing (Figure 5). Expansion of air behind wing tips is expected to cool the air by $20^{\circ}$ (Gierens et al., 2009). However, if the actual streamer formation height is above the detected streamer initiation altitude, then the temperatures may indeed be cold enough. Alternatively, APIPs are generated by ice nuclei, which become active at colder temperatures (Woodley et al., 1991).

\section{Conclusions}

Here we have reported that LIP events are formed when an aircraft penetrate a liquid layer and the subsequent adiabatic cooling either causes homogenous freezing of liquid cloud droplets or activates ice nuclei. The newly formed ice crystals appear to increase the snowflake number concentration in the preexisting precipitation. We advocate that the increase in ice number concentration leads to higher probability of ice-ice collisions and therefore to initiation of aggregation growth of snowflakes. This hypothesis is supported by

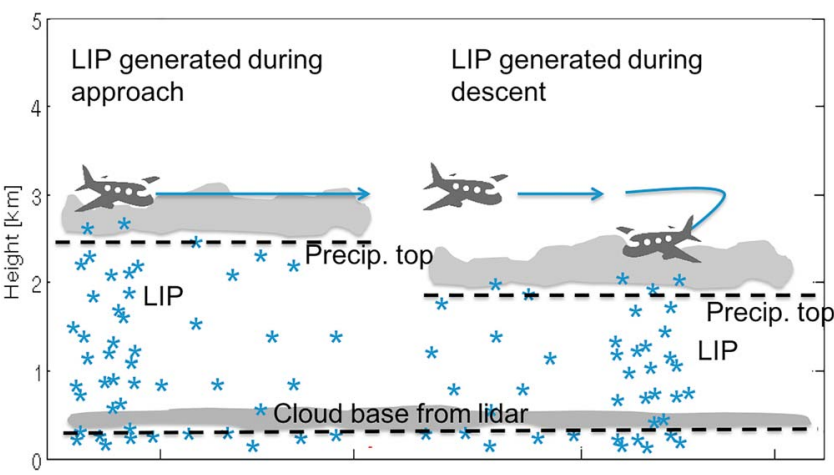

Figure 11. Schematic showing the two types of localized intensification of precipitation (LIP) analyzed in this study. the surface observations of the evolution of $N_{t}$ and $\Lambda$ as the LIP passed over the ground measurement site in Järvenpää; during the event we detected an increase in $N_{t}$ values accompanied by a reduction in $\Lambda$ values. This process appears to be responsible for the abrupt intensification of snowfall by a factor of 6 to 14. Dual-polarization radar observables, such as $Z_{\mathrm{dr}}$ and $\rho_{\mathrm{hv}}$, show a clear response, with differential reflectivity values detectably lower and copolar correlation coefficient values higher within a LIP event.

Even though our study supports the hypothesis that the LIP has an anthropogenic cause, the reported phenomenon demonstrates how cloud-to-precipitation processes work in mixed-phase clouds and what processes could be responsible for the intensification of precipitation occurring under natural conditions. 
Acknowledgments

The authors would like to thank Andy Heymsfield and two anonymous reviewers for constructive and helpful comments that has helped to improve this paper. The research of Dmitri Moisseev and Matti Leskinen was supported by the Academy of Finland (grant 305175) and the Academy of Finland Finnish Centre of Excellence program (grant 307331). Dmitri Moisseev also acknowledges the funding received from ERA-PLANET, transnational project iCUPE (grant agreement 689443), funded under the EU Horizon 2020 Framework Programme. The data used in this study are available from EUDAT B2SHARE service (Moisseev \& Leskinen, 2018). The aircraft flight track data is available from https://planefinder.net/ (last accessed on 29 May 2018)

\section{References}

Giangrande, S. E., Toto, T., Bansemer, A., Kumjian, M. R., Mishra, S., \& Ryzhkov, A. V. (2016). Insights into riming and aggregation processes as revealed by aircraft, radar, and disdrometer observations for a 27 April 2011 widespread precipitation event. Journal of Geophysical Research: Atmospheres, 121, 5846-5863. https://doi.org/10.1002/2015JD024537

Gierens, K., Kärcher, B., Mannstein, H., \& Mayer, B. (2009). Aerodynamic contrails: Phenomenology and flow physics. Journal of the Atmospheric Sciences, 66, 217-226. https://doi.org/10.1175/2008JAS2767.1

Helmus, J. J., \& Collis, S. M. (2016). The Python ARM Radar Toolkit (Py-ART), a library for working with weather radar data in the Python programming language. Journal of Open Research Software, 4(1), e25. http://doi.org/10.5334/jors.119

Heymsfield, A. J., Kennedy, P. C., Massie, S., Schmitt, C., Wang, Z., Haimov, S., \& Rangno, A. (2010). Aircraft-induced hole punch and canal clouds: Inadvertent cloud seeding. Bulletin of the American Meteorological Society, 91(6), 753-766. https://doi.org/10.1175/ 2009BAMS2905.1

Heymsfield, A. J., Thompson, G., Morrison, H., Bansemer, A., Rasmussen, R. M., Minnis, P., et al. (2011). Formation and spread of aircraftinduced holes in clouds. Science, 333(6038), 77-81. https://doi.org/10.1126/science.1202851

Hirsikko, A., O'Connor, E. J., Komppula, M., Korhonen, K., Pfüller, A., Giannakaki, E., et al. (2014). Observing wind, aerosol particles, cloud and precipitation: Finland's new ground-based remote-sensing network. Atmospheric Measurement Techniques, 7(5), 1351-1375. https://doi.org/10.5194/amt-7-1351-2014

Hobbs, P. V., Chang, S., \& Locatelli, J. D. (1974). The dimensions and aggregation of ice crystals in natural clouds. Journal of Geophysical Research, 79(15), 2199-2206. https://doi.org/10.1029/JC079i015p02199

Hogan, R. J., Illingworth, A. J., O'Cconnor, E. J., \& Baptista, J. P. V. P. (2003). Characteristics of mixed-phase clouds. II: A climatology from ground-based lidar. Quarterly Journal of the Royal Meteorological Society, 129(592), 2117-2134. https://doi.org/10.1256/qj.01.209

Huang, G.-J., Bringi, V., Moisseev, D., Petersen, W., Bliven, L., \& Hudak, D. (2015). Use of 2D-video disdrometer to derive mean densitysize and Ze-SR relations: Four snow cases from the light precipitation validation experiment. Atmospheric Research, 153, 34-48. https:// doi.org/10.1016/j.atmosres.2014.07.013

Keat, W. J., \& Westbrook, C. D. (2017). Revealing layers of pristine oriented crystals embedded within deep ice clouds using differential reflectivity and the copolar correlation coefficient. Journal of Geophysical Research: Atmospheres, 122, 11,737-11,759. https://doi.org/ 10.1002/2017JD026754

Kumjian, M. R., Mishra, S., Giangrande, S. E., Toto, T., Ryzhkov, A. V., \& Bansemer, A. (2016). Polarimetric radar and aircraft observations of saggy bright bands during MC3E. Journal of Geophysical Research: Atmospheres, 121, 3584-3607. https://doi.org/10.1002/ 2015JD024446

Kumjian, M. R., Rutledge, S. A., Rasmussen, R. M., Kennedy, P. C., \& Dixon, M. (2014). High-resolution polarimetric radar observations of snow-generating cells. Journal of Applied Meteorology and Climatology, 53(6), 1636-1658, https://doi.org/10.1175/JAMC-D-13-0312.1. https://doi.org/10.1175/JAMC-D-13-0312.1

Li, H., Moisseev, D., \& von Lerber, A. (2018). How does riming affect dual-polarization radar observations and snowflake shape? Journal of Geophysical Research: Atmospheres, 123. https://doi.org/10.1029/2017JD028186

Moisseev, D., Lautaportti, S., Tyynela, J., \& Lim, S. (2015). Dual-polarization radar signatures in snowstorms: Role of snowflake aggregation. Journal of Geophysical Research: Atmospheres, 120, 12,644-12,655. https://doi.org/10.1002/2015JD023884

Moisseev, D., \& Leskinen, M. (2018). Inadvertent localized intensification of precipitation by aircraft - Data. http://doi.org/10.23728/ b2share.6d28543e99c440c890e32d4d688a4426, (last access: 29 May 2018).

Moisseev, D., von Lerber, A., \& Tiira, J. (2017). Quantifying the effect of riming on snowfall using ground-based observations. Journal of Geophysical Research: Atmospheres, 122, 4019-4037. https://doi.org/10.1002/2016JD026272

Newman, A. J., Kucera, P. A., \& Bliven, L. F. (2009). Presenting the snowflake video imager (SVI). Journal of Atmospheric and Oceanic Technology, 26(2), 167-179. https://doi.org/10.1175/2008JTECHA1148.1

Pedgley, D. E. (2008). Some thoughts on fallstreak holes. Weather, 63(12), 356-360. https://doi.org/10.1002/wea.279

Rangno A., \& Hobbs, P. (1983). Production of ice particles in clouds due to aircraft penetrations. Journal of Climate and Applied Meteorology, 22, 214-232. https://doi.org/10.1175/1520-0450(1983)022<0214:POIPIC >2.0.CO;2

Rangno A., \& Hobbs, P. (1984). Further observations of the production of ice particles in clouds by aircraft. Journal of Climate and Applied Meteorology, 23, 985-987. https://doi.org/10.1175/1520-0450(1984)023<0985:FOOTPO >2.0.CO;2

Saltikoff, E., Huuskonen, A., Hohti, H., Koistinen, J., \& Järvinen, H. (2010). Quality assurance in the FMI Doppler weather radar network. Boreal Environment Research, 15, 579-594.

Schrom, R. S., \& Kumjian, M. R. (2016). Connecting microphysical processes in Colorado winter storms with vertical profiles of radar variables. Journal of Applied Meteorology and Climatology, 55(8), 1771-1787. https://doi.org/10.1175/JAMC-D-15-0338.1

Verlinde, J., Rambukkange, M. P., Clothiaux, E. E., McFarquhar, G. M., \& Eloranta, E. W. (2013). Arctic multilayered, mixed-phase cloud processes revealed in millimeter-wave cloud radar Doppler spectra. Journal of Geophysical Research: Atmospheres, 118, 13,199-13,213. https://doi.org/10.1002/2013JD020183

von Lerber, A., Moisseev, D., Bliven, L. F., Petersen, W., Harri, A., \& Chandrasekar, V. (2017). Microphysical properties of snow and their link to Ze-S relations during BAECC 2014. Journal of Applied Meteorology and Climatology, 56(6), 1561-1582. https://doi.org/10.1175/ JAMC-D-16-0379.1

Vonnegut, B. (1986). Nucleation of ice crystals in supercooled clouds caused by passage of an airplane. Journal of Climate and Applied Meteorology, 25(1), 98-98. https://doi.org/10.1175/1520-0450(1986)025<0098:NOICIS >2.0.CO;2

Westbrook, C., \& Davies, O. (2010). Observations of a glaciating hole-punch cloud. Weather, 65(7), 176-180. https://doi.org/10.1002/ wea.504

Woodley, W. L., Gordon, G., Henderson, T. J., Vonnegut, B., Rosenfeld, D., \& Detwiler, A. (2003). Aircraft-produced ice particles (APIPs) Additional results and further insights. Journal of Applied Meteorology, 42(5), 640-651. https://doi.org/10.1175/1520-0450(2003)042 <0640:AIPAAR>2.0.CO;2

Woodley, W. L., Henderson, T. J., Vonnegut, B., Gordon, G., Breidenthal, R., \& Holle, S. M. (1991). Aircraft-produced ice particles (APIPs) in Supercooled clouds and the probable mechanism for their production. Journal of Applied Meteorology, 30(11), 1469-1489. https://doi. org/10.1175/1520-0450(1991)030<1469:APIPIS >2.0.CO;2 